\title{
Thermoforming of a Polystyrene Sheet with a Vibrating Male Mold
}

\author{
Emil Sasimowski ${ }^{*}$, Przemysław Filipek ${ }^{2}$ \\ 1 Department of Polymer Processing and Technology, Faculty of Mechanical Engineering, Lublin University of \\ Technology, ul. Nadbystrzycka 36, 20-618 Lublin, Poland \\ 2 Department of Machine Design and Mechatronic, Faculty of Mechanical Engineering, Lublin University of \\ Technology, ul. Nadbystrzycka 36, 20-618 Lublin, Poland \\ * Corresponding author's e-mail: e.sasimowski@pollub.pl
}

\begin{abstract}
The objective of the study was to present the results of research on the thermoforming process using a patented, original male mold vibrating with the adequate frequency during the stretching of a polystyrene sheet. The research included determining the influence pertaining to the frequency of the mold vibration as well as other selected conditions of the thermoforming process, such as the temperature of the heater and heating time on the irregularity of the wall thickness of the formed product. The research was conducted using the DOE methods - central composite design. The thermoforming process was conducted using the vacuum stretching method with initial forming by high-pressure air. The analysis of the results obtained showed that the frequency of mold vibration has a significant statistic influence on the thickness of the walls of a finished product, both in the area of their bottom as well as the bottom's edge. The thickness of the product wall on these areas is also significantly influenced by the other abovementioned factors. No interaction, however, was detected between those and the frequency of the mold vibration. Using the vibrating mold in the presented process proved favourable, since the walls of the obtained finished products showed lesser irregularity in terms of the wall thickness than the products manufactured using a fixed mold.
\end{abstract}

Keywords: processing technology, thermoforming, mold's vibration, polystyrene sheet

\section{INTRODUCTION}

The process of thermoforming of a polystyrene sheets and films is used most often for the manufacturing of disposable packagings, containers, cups, trays as well as casings, dashboards and structural elements of various machines and devices. After plasticization of the sheet or film located in the forming mold, tensile stresses are induced, which leads to its deformation and adhesion to the mold cavity. Thereafter, the formed product is cooled and released $[15,16]$.

The plasticized sheet is subjected to various stresses and deformations in different areas of its surface. As a result, a significant irregularity of the thickness of the obtained productss walls occurs, which constitutes the greatest problem of the thermoforming process $[1,14]$. It is especially noticeable in the difference between the bottom and side areas of the formed product [7, 19].

In the majority of cases, both the basic vacuum forming process - stretching with lowpressure air and forming with high-pressure air (bubble and drape assisted vacuum forming) do not ensure the required, similar thickness of walls $[3,4,9]$. In order to minimize the aforementioned differences, various stretching methods are combined [6]. In the most frequently applied process, the polystyrene sheet is plasticized, preliminarily stretched and formed with either low- or highpressure air, depending on the construction of the thermoforming machine.

Preliminary stretching can also be conducted by pressing in a special rounded mold at either room or higher temperature. As a result of preliminary stretching [17] the entire material is 
evenly deformed and its surface area maximized. The surface area of the sheet is always smaller than the surface area of the mold cavity. In the following stage of the process, the material can also be stretched by the forming mold pressing into it. Afterwards, the final stretching and forming according to the shape of the mold or die [13, 18] occurs by the methods presented above.

One of the solutions used to increase the surface of the stretched material is using a clamp frame, which allows the sheet to partially slide out during stretching.

The thickness of walls can also be influenced by thermal processes, determining the plasticization and deformability of the material. In that case, automatic temperature control systems are used and the material is locally covered during the heating process.

This paper presents a state-of-the-art, patented method and construction solutions of thermoforming [12], which allows for minimizing the differences in wall thicknesses of the manufactured products.

In this method, the mold is equipped with an electric vibration motor. Its vibration frequency can be modified depending on the requirements. Furthermore, between the mold and the table vibration isolators, motor working in low frequencies (Fig. 1) are located.

In the improved thermoforming process, the polystyrene sheet is fixed using a clamp frame (Fig. 1a) and heated to a temperature at which plasticization occurs by a heater (Fig. 1b). The sheet stretched by compressed air flowing between the sheet and the body of the machine (Fig. 1c). Furthermore, the sheet is stretched as a result of the reciprocating motion of the table by pushing the vibrating mold into the sheet. The vibrating motion of the mold is caused by the electric vibration motor (Fig. 1d). This, in turn, constitutes the new thermoforming process.

The final forming of the product occurs by low air-pressure stretching (vacuum stretching) - suction of air from between the mold and the shaped material (Fig. 1e). Afterwards, the shaped product is cooled. In this method, a more regular stretching of the sheet is ensured and, as a result, the friction between the material and the vibrating mold decreases.

The objective of the study was to determine the influence of the frequency of vibration as well as the temperature of the heater and heating time on various wall thicknesses of the manufactured products.

\section{EXPERIMENTAL}

\section{Laboratory stand}

The tests were conducted using a modified PEX B-3 F thermoforming setup (Fig. 2).

The stand is equipped with HTS type ceramic infrared radiators with a total power of $3.6 \mathrm{~kW}$, located $130 \mathrm{~mm}$ away from the heated surface [5]. The radiators are placed in such a way that they create two heating zones. A scheme of the radiators location is presented in the study [11]. On the inner outline of the clamp, frame reflectors are located. The aim of reflectors is to compensate for the irregularity of the sheet heating, caused by a different intensity with which heat radiation impacts the surface. The stand is also equipped with a $0.75 \mathrm{~kW}$ vacuum pump, producing pressure equal to $2 \mathrm{hPa}$.

The original stand was modified in such a way that an electric vibrating motor, emitting low-frequency vibrations $(0-60 \mathrm{~Hz})$ was placed (fig. 3a) in a partially hollowed-out mold (Fig. 3b).

A $12 \mathrm{~V}$ electric brush engine constitutes the major element of the electric vibrating motor. On its shaft, an unbalanced steel roll was placed eccentrically. As a result of the rotation of the roll, vibration of the entire vibrating motor occurs, which, in turn, causes the remaining parts of the casing to vibrate.

The mold is fixed to the movable table using vibration isolators - rubber rolls (Fig. 3a, 3b). The mold, in the shape of a truncated pyramid, with rounded edges, was made of MDF. Its dimensions are as follows: height: $100 \mathrm{~mm}$, dimensions of the base: $345 \times 200 \mathrm{~mm}$ and the summit 310x160 mm. The control system was modified to allow for an electronic regulation of the vibration frequency.

\section{Research method}

In the research, a $0.5 \mathrm{~mm}$ thick, high-impact polystyrene sheet (HIPS), produced by P.P.H.U Petroplast Sp. z o.o. was used.

In the experiment, the following independent factors were considered:

- heating time $(\mathrm{t}), \mathrm{s}$;

- temperature of the heater $(\mathrm{T}),{ }^{\circ} \mathrm{C}$;

- vibration frequency (f), Hz.

Constant parameters included: vacuum time $6 \mathrm{~s}$, cooling time $5 \mathrm{~s}$, duration and frequency of the compressed air impulses for separating the 
a)

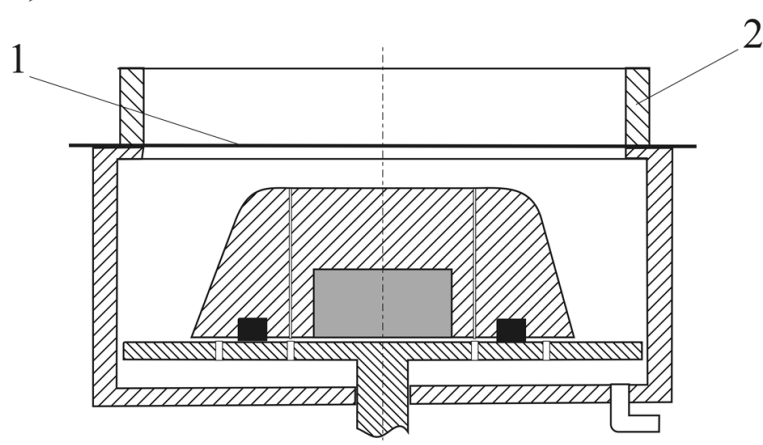

b)

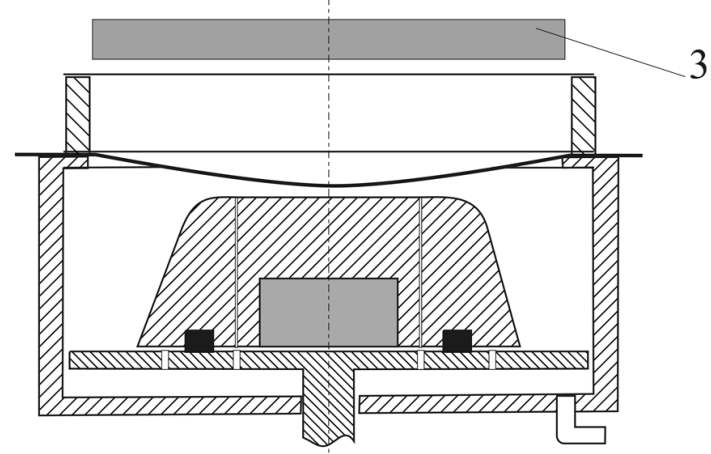

c)

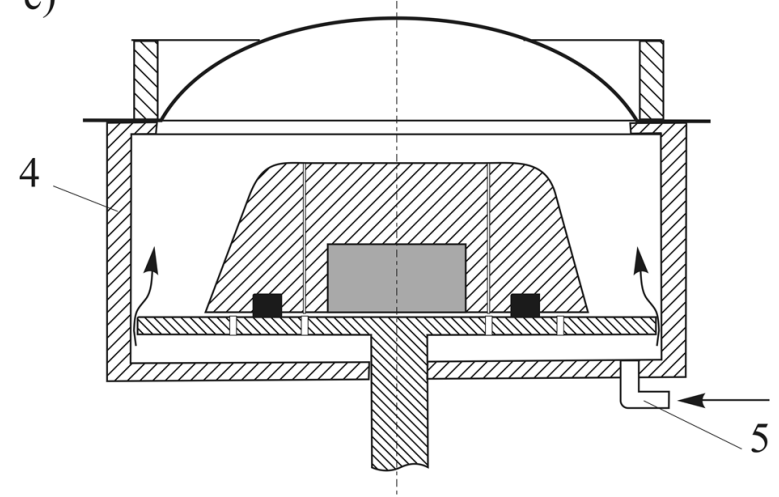

d)

2

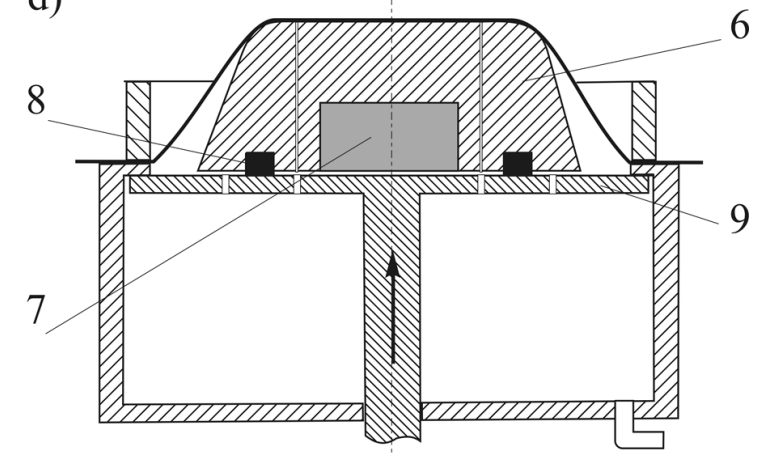

e)

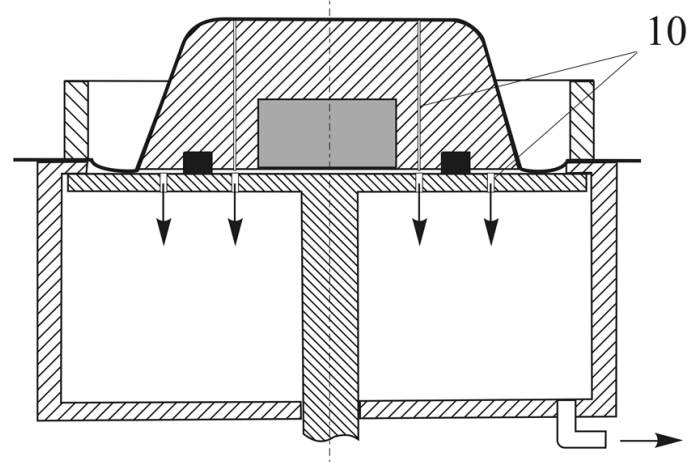

Fig. 1. Stages of the thermoforming process, a) fixing the polystyrene sheet, b) heating the sheet, c) preliminary stretching of the sheet, d) stretching by pressing in the vibrating mold, e) vacuum stretching of a sheet: 1 - sheet, 2 - clamp frame, 3 - heater, 4 - body, 5 - suction-force pressure channel, 6 - male mold, 7 - electric vibration motor, 8 - vibration isolators, 9 - movable table, 10 - air flow channels

finished part from the male mold amount to $1 \mathrm{~s}$, $2 \mathrm{~Hz}$, pressure of the compressed air in the working set of the laboratory stand $0.33 \mathrm{MPa}$.

The bubble time was maintained constant at the lowest value possible, i.e. at $1 \mathrm{~s}$. According to the preliminary tests, longer bubble time is connected to the corrugations occurring at the bottom of the manufactured products.

The wall thicknesses of the finished products (g) were measured in certain points on the crosssection, shown in Figure 4. The measurements were taken with the accuracy of $0.001 \mathrm{~mm}$ with an electronic micrometer. Depending on the point of measurement, a flat or spherical end was used.
The preliminary tests allowed for determining the independent variables $(\mathrm{t}) \in(18$ to 28$) \mathrm{s}$, $(\mathrm{T}) \in(386$ to 454$){ }^{\circ} \mathrm{C}$ and $(\mathrm{f}) \in(0$ to 58$) \mathrm{Hz}$. A rotable central composite design with the star point distance $\alpha$ set to 1.6818 was adopted [8]. Six repetitions were planned, which resulted in 20 measuring sets. Table 1 presents the experimental designs of the research plan, according to which the measurements were taken.

The tests allowed for the approximation of the dependencies between the dependent variables - thicknesses of walls in the measurement points and the independent variables $(\mathrm{T}),(\mathrm{t})$ and (f) using multivariate polynomials consisting of 


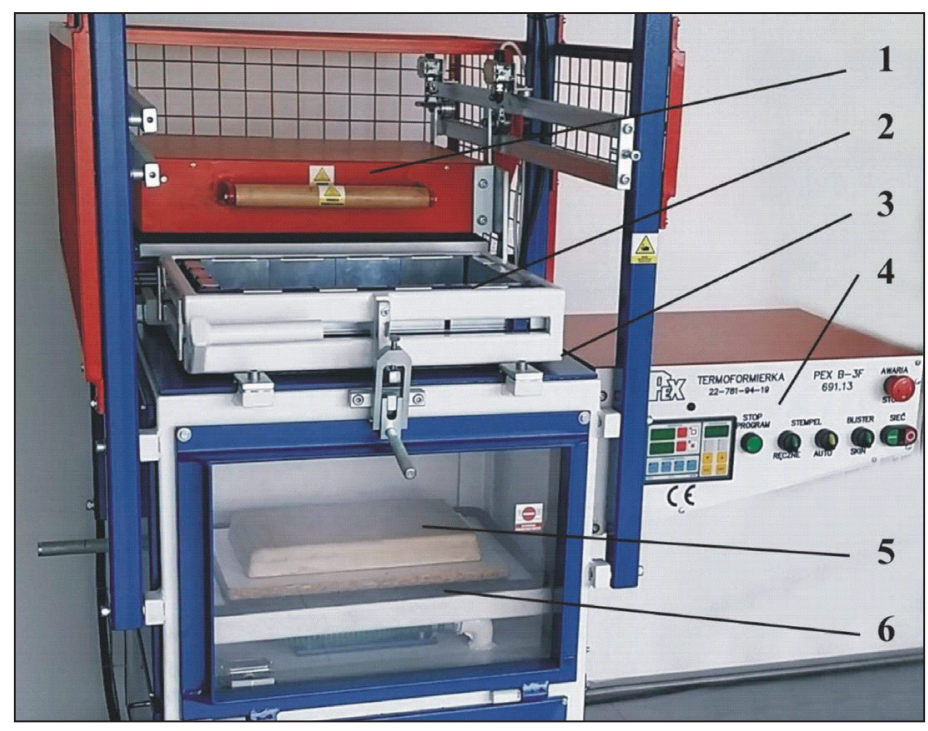

Fig. 2. PEX B-3 F thermoforming stand: 1 - heater, 2 - clamp frame, 3 - fixed table, 4 - control system, 5 - mold, 6 - movable table

a)

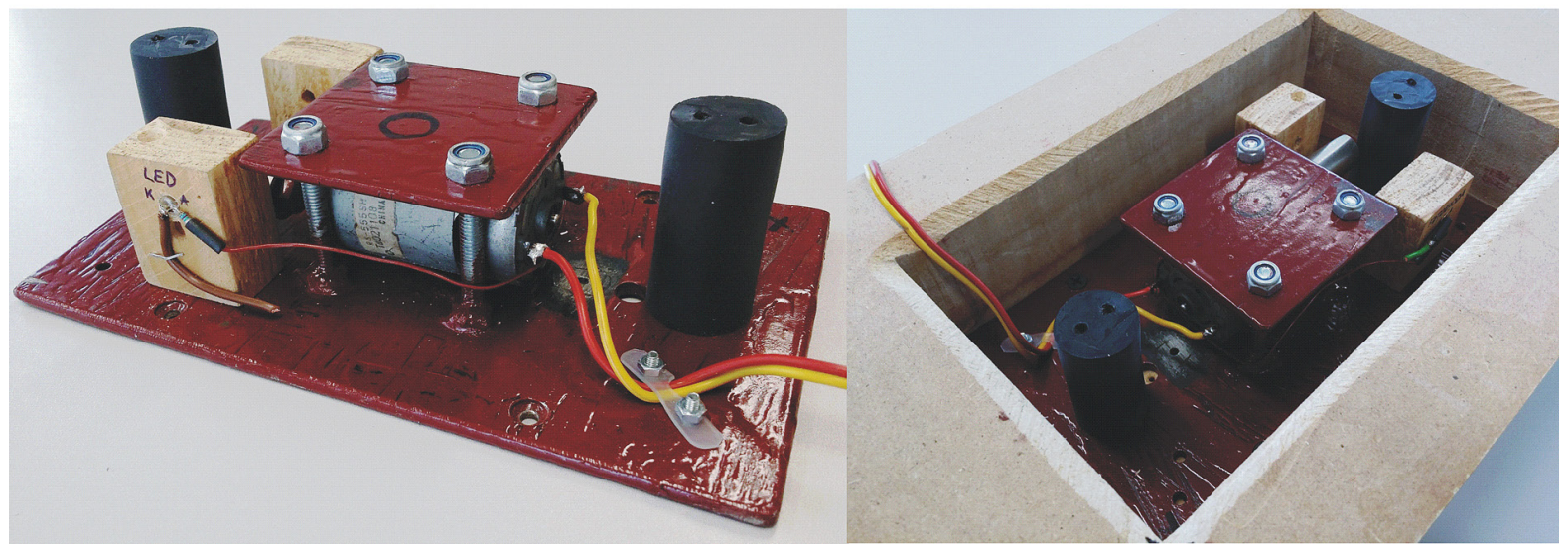

Fig. 3. Electric vibrating motor with an electronically-regulated vibration frequency: a) module, b) location of the electric vibrating motor

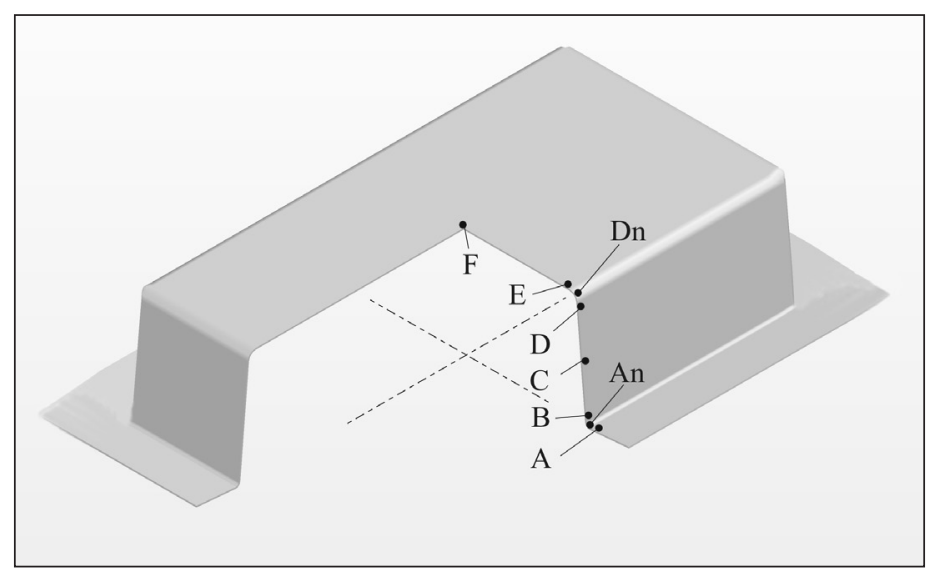

Fig. 4. Scheme of the finished product, A-F measurement points of the wall thickness in the cross-section 
Table 1. Plan of the experimental tests

\begin{tabular}{|c|c|c|c|}
\hline Plan design & $\mathrm{T},{ }^{\circ} \mathrm{C}$ & $\mathrm{t}, \mathrm{s}$ & $\mathrm{f}, \mathrm{Hz}$ \\
\hline 1 & 400 & 20 & 12 \\
\hline 2 & 400 & 20 & 46 \\
\hline 3 & 400 & 26 & 12 \\
\hline 4 & 400 & 26 & 46 \\
\hline 5 & 440 & 20 & 12 \\
\hline 6 & 440 & 20 & 46 \\
\hline 7 & 440 & 26 & 12 \\
\hline 8 & 440 & 26 & 46 \\
\hline 9 & 386 & 23 & 29 \\
\hline 10 & 454 & 23 & 29 \\
\hline 11 & 420 & 18 & 29 \\
\hline 12 & 420 & 28 & 29 \\
\hline 13 & 420 & 23 & 0 \\
\hline 14 & 420 & 23 & 58 \\
\hline $15-20(\mathrm{C})$ & 420 & 23 & 29 \\
\hline
\end{tabular}

linear elements, quadratic elements and two-factor interaction elements.

The results of the tests were analysed using variance analysis in Statistica 13 software. In order to present the statistical assessment of the influence of each regression element on the value of the modelled dependent variable, the Pareto analysis was used [8]. The vertical line noticeable in Pareto chart shows the statistical significance level $\mathrm{p}=0.05$ and the absolute values of the standardized effects that exceed this level are deemed statistically significant.

\section{RESULTS AND DISCUSSION}

The measurements validated the usage of the vibrating male mold, since it causes a significant change in the wall thickness of the finished product in certain measurement points. As a result of the vibrating motion of the mold, the thickness of the product wall changes in a statistically significant manner in points $\mathrm{F}$ and $\mathrm{E}$, located on the bottom of the product as well as in the Dn point located on the rounded edge of the bottom. The Pareto analysis (Fig. 5-7) proved that the changes in wall thickness are influenced by the vibration frequency and that this dependency can be described by a quadratic function. No significant influence, however, was noticed as far as the dependency between the vibration frequency and wall thickness in other measuring points is concerned. This phenomenon is caused by the fact that the sheet is subjected to vacuum stretching in the points from $\mathrm{D}$ to $\mathrm{A}$. This phenomenon occurs in the final stage of the thermoforming process, after stretching using the mold.

The Pareto analysis also shows that both heating time and heater temperature have a significant influence on wall thickness in (F) measurement point located in the middle of the product bottom and (E) the measurement point located on the bottom's edge. Those factors have a negative effect - growth of those values causes a decrease to the wall thickness and is linear, whereas for temperature-quadratic. The interaction between the aforementioned factors was also noticed in the (F) point. In the (Dn) point, apart from vibration frequency the heater temperature is statistically significant.

On the basis of the analysis of regression models obtained using Statistica 13 software, 3D charts illustrating the influence of the vibration frequency, sheet heating time and heater temperature on the wall thickness were created. It allowed for an analysis of the influence of the selected factors on wall thickness in the F, E and Dn measurement points (Fig. 8-12).

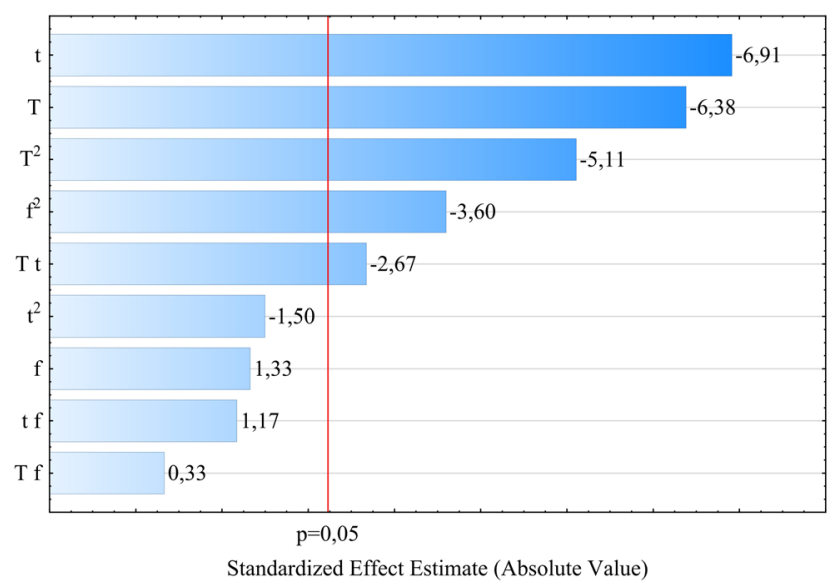

Fig. 5. Results of the Pareto analysis of the standardized effects of the regression model of wall thickness in the $(\mathrm{F})$ point 


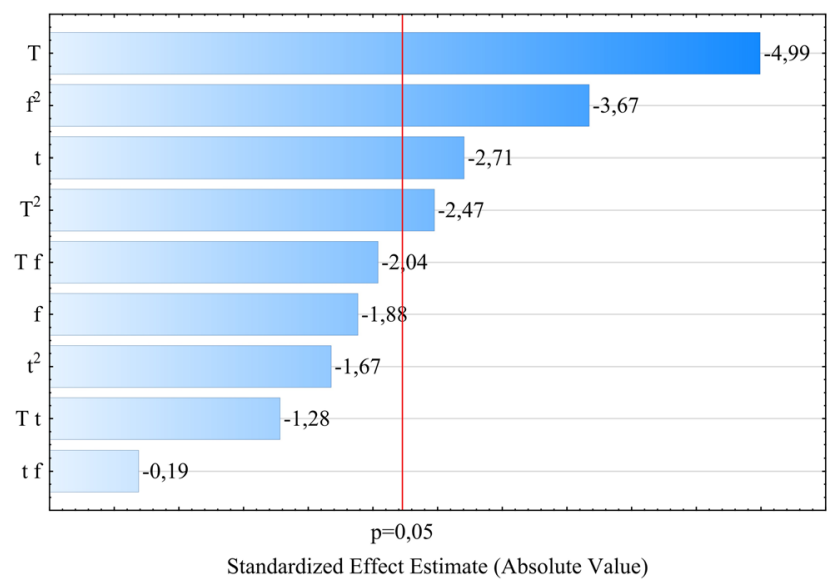

Fig. 6. Results of the Pareto analysis of the standardized effects of the regression model of wall thickness in the (E) point

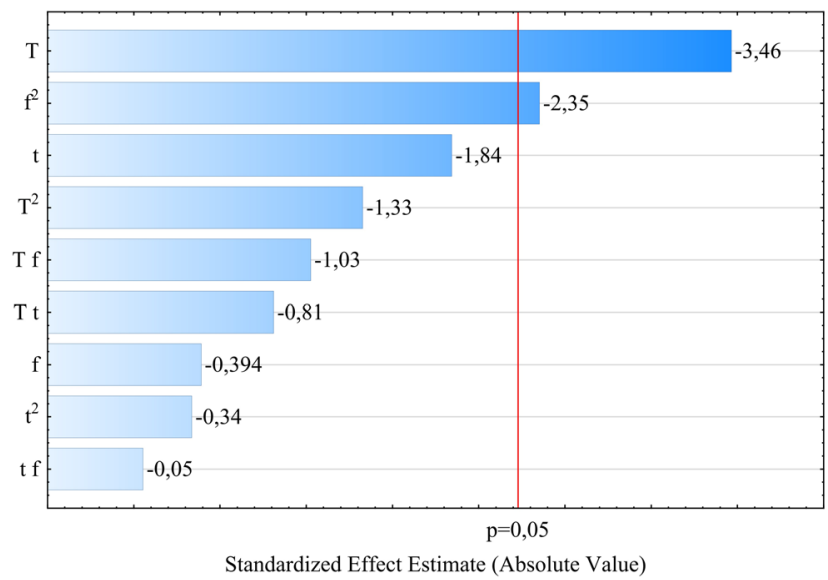

Fig. 7. Results of the Pareto analysis of the standardized effects of the regression model of wall thickness in the (Dn) point

The (F), (E) and (Dn) points show a similar influence of the vibration frequency on the wall thickness. The highest wall thickness occurs at the vibration frequency equal to the center of the experiment plan. The area of the highest wall thickness is linked to the vibration frequency (f) $29 \pm 10 \mathrm{~Hz}$. Should those values be lower or higher, the wall thickness of the product decreases.

An increase of the wall thickness in the bottom area, as a result of using a vibrating mold allows for reducing the wall thickness differences in the cross-section of the products (Fig. 13). Using a mold with the vibration frequency $\mathrm{f}=29 \mathrm{~Hz}$, when the remaining factors are the same allows for achieving greater regularity in terms of the thickness of the wall (points A-D) and the bottom of the product (the Dn, E, F points).

In the (F), (E) and (Dn) measurement points, the influence of other factors is also similar.
Increasing the heating time causes a decrease of the product wall thickness. The lowest values occur when the heating time is the longest (28 s). Increasing the heater temperature has the same influence on the wall thickness. The lowest values occur when the temperature is the highest $\left(454{ }^{\circ} \mathrm{C}\right)$. Increasing the values of the both factors causes a significant increase of the sheet's temperature, which was illustrated by the results of the thermal imaging presented in the study [11].

The sheet temperature has a significant influence on its plasticization and deformability. High temperature of the process sheet causes an excessive thinning of the product's walls, while achieving its good shape. As far as low temperatures are concerned, it can cause deficient deformability and occurrence of defects and, as a result, an insufficient forming in the areas that are stretched in the final stages of the process. 


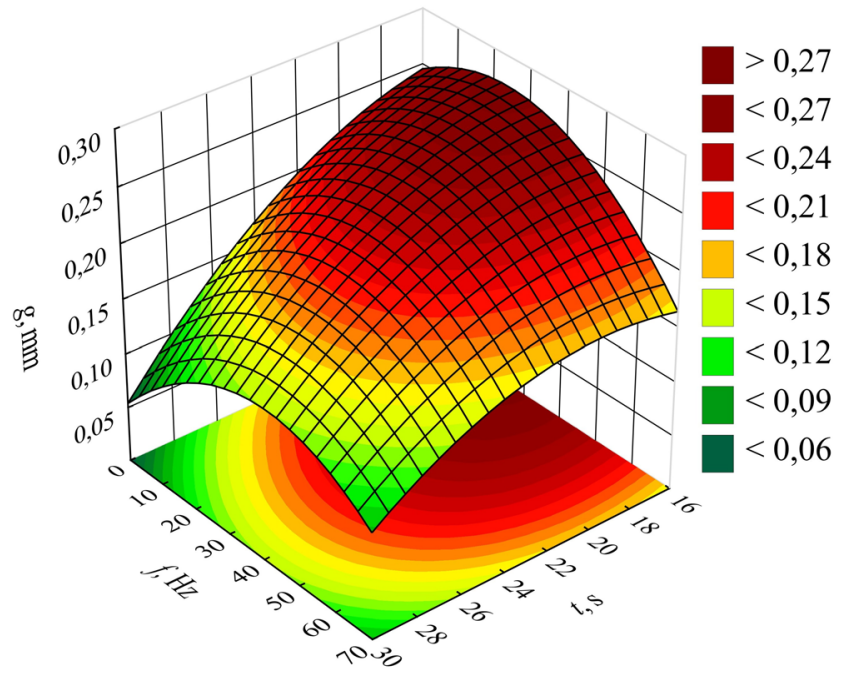

Fig. 8. Wall thickness of the product $(\mathrm{g})$ in the $(\mathrm{F})$ point depending on the mold vibration frequency (f) and heating time ( $\mathrm{t}$ ), when the temperature of the heater $\mathrm{T}=420^{\circ} \mathrm{C}$

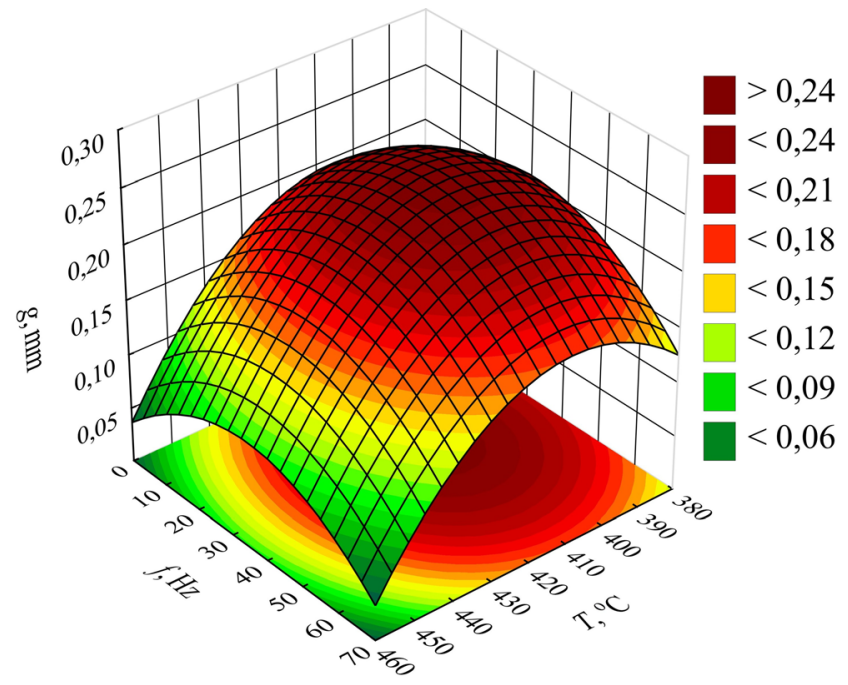

Fig. 9. Wall thickness of the product (g) in the (F) point depending on the mold vibration frequency (f) and heating time ( $\mathrm{t}$ ), when heating time $\mathrm{t}=23 \mathrm{~s}$

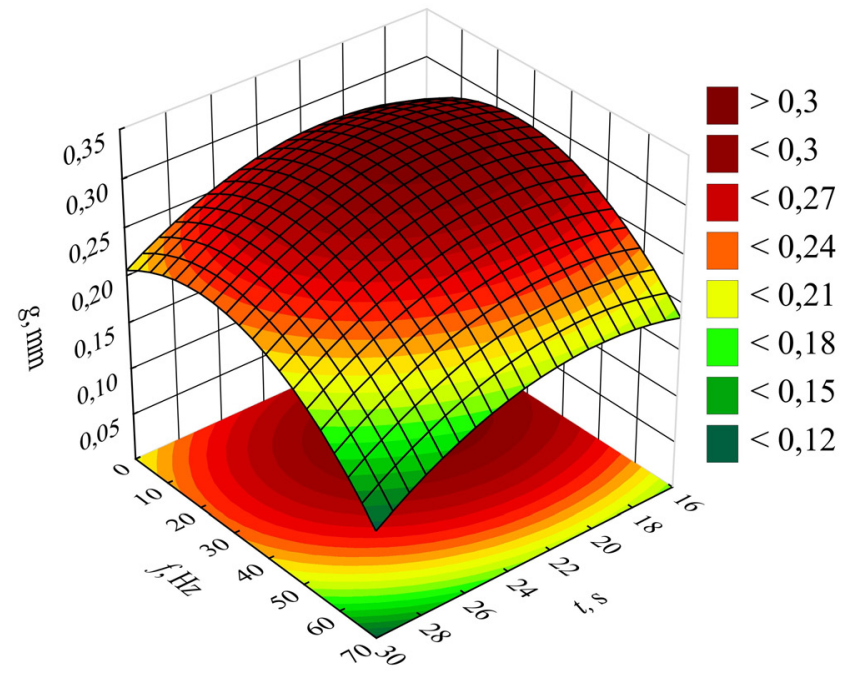

Fig. 10. Wall thickness of the product (g) in the (E) point depending on the mold vibration frequency (f) and heating time $(\mathrm{t})$, when heater temperature $\mathrm{T}=420^{\circ} \mathrm{C}$ 


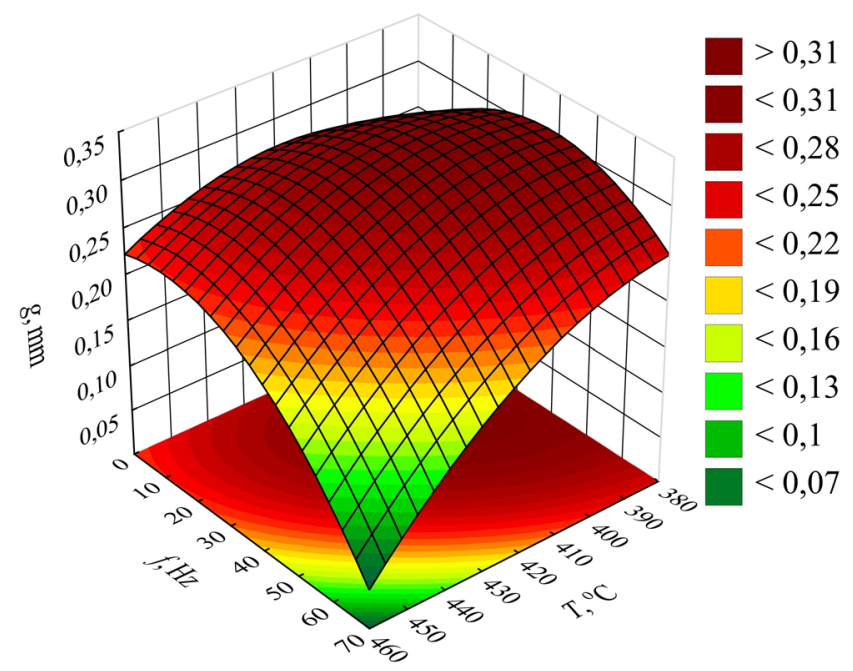

Fig. 11. Wall thickness of the product (g) in the (E) point depending on the mold vibration frequency (f) and the heater temperature (T), when heating time $t=23 \mathrm{~s}$

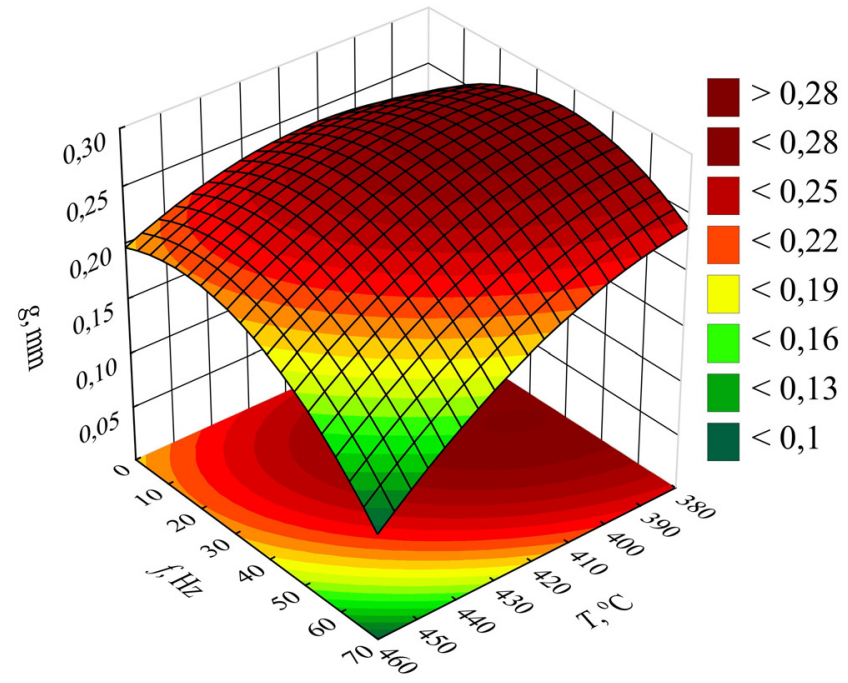

Fig. 12. Wall thickness of the product $(\mathrm{g})$ in the (Dn) point depending on the mold vibration frequency (f) and heater temperature (T), when heating time $t=23 \mathrm{~s}$

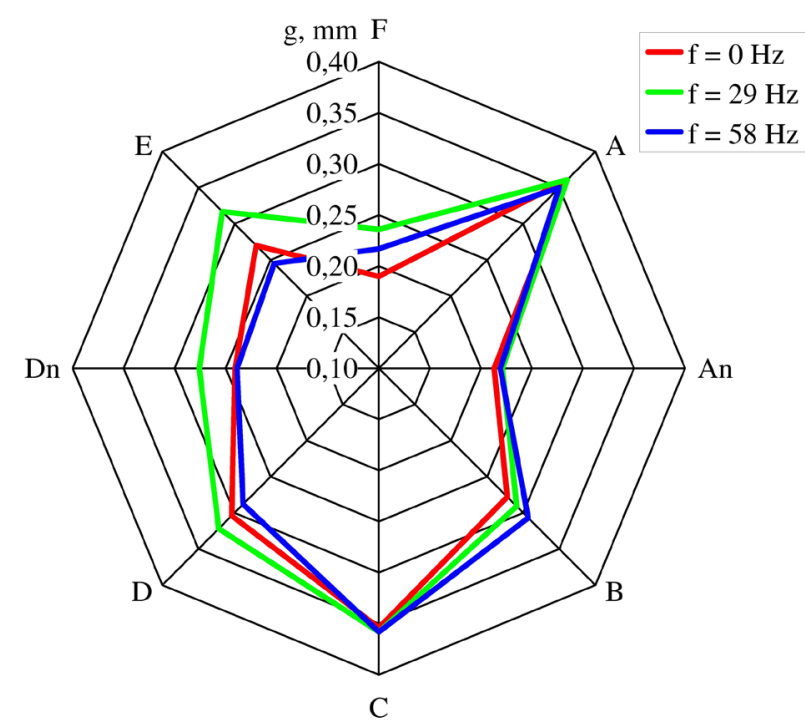

Fig. 13. Changes in wall thickness in the measurement points, depending on the mold vibration frequency, at heater temperature $\mathrm{T}=420^{\circ} \mathrm{C}$ and heating time $\mathrm{t}=23 \mathrm{~s}$ 


\section{CONCLUSIONS}

To sum up, it can be stated that implementing the modified, thermoforming process above described can significantly decrease the irregularities in the thickness of side walls and the bottom of the manufactured product. The conducted analyses allowed for determining the influence of the thermoforming process factors and its character on the wall thickness measured in various points of the product. It was also observed that the positive impact of the mold on decreasing the irregularity of the wall and bottom thicknesses occurs with the vibration frequency $\mathrm{f}=29 \pm 10 \mathrm{~Hz}$. The mold vibration significantly influences the wall thickness in the area of the bottom and side walls of the product, which is caused by the fact that this area is mostly subjected to stretching by the mold. No significant influence of the mold vibration frequency on wall thickness was observed in other measuring points of the product, since those are mostly subjected to vacuum stretching. In order to obtain the product with the most similar wall thicknesses, it is advised to maintain the researched values of low heater temperature as well as heating time. In the interaction between the mold vibration frequency, heater temperature and heating time has been observed.

Further research on the process of thermoforming with a vibrating mold seems relevant in terms of both the cognitive and practical approach, especially focusing on: other shapes of the formed products and materials of which the molds are made, as well as the influence of their roughness on the geometric features of the obtained products.

\section{REFERENCES}

1. Engelmann S. Advanced Thermoforming: Methods, Machines and Materials, Applications and Automation, John Wiley \& Sons, UK. Chichester, 2012. DOI: 10.1002/9781118207086.ch31

2. Haihong $\mathrm{Xu} \mathrm{H}$. and Kazmer D.O. Thermoforming shrinkage prediction. Polymer Engineering \& Science 9(41), 2001, 1553-1563. DOI: 10.1002/ pen. 10854

3. Hosseini H. and Vasilivich Berdyshev B. A Solution for the Rupture of Polymeric Sheets in Plug-Assist Thermoforming. Journal of Polymer Research 4(13), 2006, 329-334. DOI: 10.1007/ s10965-006-9042-1
4. Hosseini H., Berdyshev B.V. and Mehrabani-Zeinabad A. Dynamic characteristics of plug-assist thermoforming process. Polymer Engineering \& Science 2(49), 2009, 240-243. DOI: 10.1002/pen.21245

5. http://www.pex.biz.pl

6. Klein P.W. Fundamentals of plastic thermoforming, Synthesis lectures on materials engineeering, Morgan \& Claypool Publishers, 2009.

7. Min S.C., Zhang H.Q. and YANG H. Thermoformed container wall thickness effects on orange juice quality. Journal of Food Processing and Preservation 6(35), 2011, 758-766. DOI: 10.1111/j.174 5-4549.2011.00526.x.

8. Montgomery D.C. Design and Analysis of Experiments 7 th. ed., Wiley\&Sons, 2009.

9. Nam G.J., Lee J.W. and Ahn K.H. Three-dimensional simulation of thermoforming process and its comparison with experiments. Polymer Engineering \& Science, 10(40), 2000, 2232-2240. DOI: $10.1002 /$ pen. 11355

10. Raurí McCool R. and Martin P. J. The role of process parameters in determining wall thickness distribution in plug-assisted thermoforming. Polymer Engineering \& Science 10(50), 2010, 1923-1934. DOI: $10.1002 /$ pen. 21718

11. Sasimowski E. The Effect of Selected Conditions in a Thermoforming Process on Wall Thickness Variations, Adv. Sci. Technol. Res. J., 11(4), 2017, 41-48. DOI: https://doi.org/10.12913/22998624/73818

12. Sasimowski E. and Filipek P. Device and method for heat forming of products from polymer plastics, Patent PL 230093 (B1) 2018.

13. Schwarzmann P. Thermoforming - A Practical Guide, Carl Hanser Verlag, Munich 2001.

14. Sykutera D. and Pepliński K. Zastosowanie programu Ansys-Polyflow do wspomagania wytwarzania opakowań formowanych próżniowo. Inż. Ap. Chem, 3(50), 2011, 73-74.

15. Throne J. L. Technology of Thermoforming, Hanser Publishers, Munich, 1996.

16. Throne J. L. Understanding thermoforming, Hanser Publishers, Munich, 2008

17. Van Mieghem B., Desplentere F., Van Bael A. and Ivens J.: Improvements in thermoforming simulation by use of 3D digital image correlation. eXPRESS Polymer Letters 2(9), 2015, 119-128. DOI: 10.3144/expresspolymlett.2015.13.

18. Żenkiewicz M. and Szach A. Recent developments in the thermoforming of polimeric materials. Polimery 5(55), 2010, 337-350. DOI:dx.doi. org/10.14314/polimery.2010.337

19. Żenkiewicz M. and Richert J. Thermoforming of polylactide nanocomposite films for packaging containers. Polimery 4(54), 2009, 299-302. 